\title{
Kolarctic CBC \\ Особенности минерального состава складированных отходов обогащения апатитсодержащих руд
}

\author{
Митрофанова Г.В., Черноусенко Е.В., Артемьев А.В., Веселова Е.Г. \\ Горный институт КНЦРАН, Anamumb, sashaartemev2009@yandex.ru
}

Аннотация. В результате увеличения объема перерабатываемых апатит-нефелиновых руд происходит накопление значительного количества складированных отходов производства. Такие техногенные месторождения представляют интерес как потенциальный объект для вовлечения в переработку. В настоящей работе изучены две пробы отходов обогащения апатит-нефелиновых руд, складированные в хвостохранилища в различные временные периоды. Выполненными минералогическими и химическими анализами показано, что нефелин в пробах находится в видоизмененном состоянии. Зерна нефелина в одной пробе частично замещены гидрослюдами, в образцах из другого хвостохранилища установлены признаки более глубокого видоизменения: по поверхности зерен наблюдаются цеолиты и глинистые минералы. Часть зерен эгирина и титанита также имеют примазки глинистых минералов. Методом сорбции красителя (голубой метиленовый) наглядно подтверждено наличие примазок или пленок тонкодисперсных глинистых частиц (в основном иллита) на поверхности зерен минералов, что создает предпосылки к усложнению получения кондиционных концентратов из такого сырья. Выявлено, что после измельчения, продиктованного необходимостью раскрытия сростков, на поверхности апатита не наблюдается налётов и примазок вторичных минералов, что определило возможность выделения его в апатитовый концентрат с содержанием $\sim 39 \% \mathrm{P}_{2} \mathrm{O}_{5}$.

Ключевые слова: отходы переработки апатит-нефелиновых руд Кольского полуострова, минералоготехнологические особенности техногенного сырья, вторичные минералы, апатит, нефелин.

\section{Specialities of mineral composition of stockpiled apatite ore processing waste}

\author{
Mitrofanova G.V., Chernousenko E.V., Artemiev A.V., Veselova E.G. \\ Mining Institute Kola Science Centre RAS, Apatity, sashaartemev2009@yandex.ru
}

\begin{abstract}
The increase in the volume of processed apatite-nepheline ores results in accumulating a considerable quantity of stockpiled production wastes. Such secondary deposits are of interest as a potential object to be involved into processing. The work given has studied two samples of apatite-nepheline ore processing waste stockpiled in the tailings in different time periods. Mineralogical and chemical analyses have shown a modified state of nepheline in the samples. The nepheline grains in one sample are partially replaced by hydromica. The samples from another tailings dump have signs of deeper modification: zeolites and clay minerals are observed on the grains' surface. Some grains of aegirine and titanite also have admixtures of clay minerals. The colorant sorption (blue methylene) method has clearly confirmed the presence of admixtures or films of finely dispersed clay particles (mainly illite) on the surface of mineral grains, which can complicate producing of conditioned concentrates from such raw materials. It has been revealed that after grinding substantiated by the necessity of aggregate liberation, the surface of apatite does not contain films and admixtures of secondary minerals. This fact has determined the potential to recover it into apatite concentrate with $\sim 39 \% \mathrm{P}_{2} \mathrm{O}_{5}$ content.
\end{abstract}

Key words: the Kola Peninsula apatite-nepheline ore processing wastes, mineralogical and technological features of secondary raw materials, secondary minerals, apatite, nepheline.

Мурманская область обладает большими запасами полезных ископаемых и развитым горнопромышленным комплексом. Однако, с ростом количества перерабатываемого сырья, увеличивается объем складированных отходов обогащения. Минеральный и химический анализы этих отходов, показывают значительное содержание в них полезных компонентов доступных для извлечения, зачастую сравнимое с содержанием их в бедных рудах, что позволяет рассматривать подобные техногенные месторождения как перспективный объект для вовлечения в переработку (Аксенов и др., 
2010). Апатитсодержащие руды, как источник фосфора для производства минеральных удобрений, являются сегодня одним из востребованных видов сырья (Трубецкой, 2010). В работе изучены особенности минерального состава отходов обогащения апатит-нефелиновых руд Хибинских месторождений, складированных в хвостохранилища в разные временные периоды.

Таблица 1. Распределение основных компонентов по классам крупности.

Table 1. Distribution of principal components by size class.

\begin{tabular}{|c|c|c|c|c|c|c|c|c|c|c|c|}
\hline \multirow{2}{*}{$\begin{array}{c}\text { Класс } \\
\text { крупности, мм }\end{array}$} & \multirow{2}{*}{$\begin{array}{c}\text { Выход, } \\
\%\end{array}$} & \multicolumn{5}{|c|}{ Содержание, \% } & \multicolumn{5}{|c|}{ Распределение, \% } \\
\hline & & $\mathrm{P}_{2} \mathrm{O}_{5}$ & $\mathrm{TiO}_{2}$ & $\mathrm{Fe}_{\text {обш. }}$ & $\begin{array}{c}\mathrm{Al}_{2} \mathrm{O}_{3} \\
\text { общщ. }\end{array}$ & $\begin{array}{l}\mathrm{Al}_{2} \mathrm{O}_{3} \\
\text { k.p. }\end{array}$ & $\mathrm{P}_{2} \mathrm{O}_{5}$ & $\mathrm{TiO}_{2}$ & $\begin{array}{l}\mathrm{Fe} \\
\text { общ. }\end{array}$ & $\begin{array}{c}\mathrm{Al}_{2} \mathrm{O}_{3} \\
\text { общ. }\end{array}$ & $\underset{\text { K.p. }}{\mathrm{Al}_{2} \mathrm{O}_{3}}$ \\
\hline \multicolumn{12}{|c|}{ Проба ПХ-1 } \\
\hline+0.315 & 2.5 & 2.0 & 0.40 & 2.64 & 26.80 & 21.84 & 3.9 & 0.3 & 1.0 & 3.1 & 2.9 \\
\hline$-0.315+0.2$ & 17.6 & 1.43 & 0.46 & 2.49 & 27.11 & 23.36 & 19.6 & 2.7 & 6.7 & 21.4 & 21.3 \\
\hline$-0.2+0.16$ & 20.4 & 1.30 & 1.04 & 3.15 & 25.68 & 22.59 & 21.0 & 7.3 & 10.0 & 23.9 & 24.3 \\
\hline$-0.16+0.1$ & 26.1 & 1.25 & 2.48 & 4.72 & 22.95 & 19.73 & 25.8 & 22.4 & 19.1 & 27.3 & 27.1 \\
\hline$-0.1+0.07$ & 21.1 & 1.14 & 5.15 & 8.65 & 17.10 & 14.85 & 19.0 & 37.6 & 28.4 & 16.4 & 16.5 \\
\hline$-0.07+0.05$ & 7.0 & 0.90 & 7.28 & 19.2 & 13.41 & 11.74 & 5.0 & 17.7 & 20.9 & 4.3 & 4.3 \\
\hline-0.05 & 5.6 & 1.28 & 6.22 & 15.9 & 14.28 & 12.39 & 5.7 & 12.0 & 13.9 & 3.6 & 3.6 \\
\hline Итого & 100.0 & 1.26 & 2.89 & 6.43 & 21.93 & 18.99 & 100 & 100 & 100 & 100 & 100 \\
\hline \multicolumn{12}{|c|}{ Проба ПХ-2-150 } \\
\hline+0.63 & 2.5 & 6.04 & 1.63 & 4.19 & 21.09 & 17.12 & 3.5 & 1.2 & 1.7 & 2.8 & 2.8 \\
\hline$-0.63+0.4$ & 11.8 & 6.81 & 1.63 & 3.56 & 20.56 & 17.09 & 18.8 & 5.5 & 6.6 & 12.8 & 13.1 \\
\hline$-0.4+0.315$ & 13.8 & 6.69 & 1.74 & 3.56 & 20.06 & 17.43 & 21.6 & 6.9 & 7.8 & 14.6 & 15.6 \\
\hline$-0.315+0.2$ & 29.5 & 4.90 & 2.54 & 5.08 & 20.65 & 17.08 & 33.9 & 21.4 & 23.6 & 32.1 & 32.8 \\
\hline$-0.2+0.16$ & 15.4 & 3.06 & 4.33 & 6.89 & 18.68 & 14.85 & 11.0 & 19.1 & 16.7 & 15.1 & 14.9 \\
\hline$-0.16+0.1$ & 12.0 & 1.99 & 5.75 & 9.47 & 16.21 & 12.68 & 5.6 & 19.7 & 17.9 & 10.2 & 9.9 \\
\hline$-0.1+0.07$ & 7.3 & 1.49 & 6.77 & 10.84 & 15.44 & 11.33 & 2.5 & 14.1 & 12.5 & 5.9 & 5.4 \\
\hline$-0.07+0.05$ & 3.9 & 1.21 & 6.37 & 10.91 & 15.72 & 10.74 & 1.1 & 7.1 & 6.7 & 3.2 & 2.7 \\
\hline-0.05 & 3.8 & 2.13 & 4.63 & 10.75 & 16.26 & 11.52 & 2.0 & 5.0 & 6.4 & 3.3 & 2.8 \\
\hline Итого & 100 & 4.27 & 3.50 & 6.34 & 18.99 & 15.38 & 100 & 100 & 100 & 100 & 100 \\
\hline \multicolumn{12}{|c|}{ Проба ПХ-2-180 } \\
\hline+0.63 & 1.0 & 3.45 & 1.59 & 3.93 & 19.25 & 18.32 & 1.2 & 0.4 & 0.6 & 1.0 & 1.0 \\
\hline$-0.63+0.4$ & 10.8 & 3.83 & 1.02 & 2.78 & 24.63 & 20.36 & 13.8 & 2.8 & 4.8 & 13.2 & 12.5 \\
\hline$-0.4+0.315$ & 14.9 & 4.24 & 1.31 & 2.85 & 23.71 & 20.62 & 21.2 & 5.0 & 6.7 & 17.5 & 17.5 \\
\hline$-0.315+0.2$ & 30.7 & 3.80 & 2.27 & 3.66 & 22.10 & 19.48 & 39.1 & 17.9 & 17.8 & 33.7 & 34.1 \\
\hline$-0.2+0.16$ & 15.0 & 2.47 & 4.88 & 6.66 & 18.66 & 16.87 & 12.4 & 18.8 & 15.8 & 13.9 & 14.4 \\
\hline$-0.16+0.1$ & 12.2 & 1.55 & 7.12 & 10.2 & 15.77 & 13.59 & 6.3 & 22.3 & 19.6 & 9.6 & 9.5 \\
\hline$-0.1+0.07$ & 7.7 & 1.13 & 8.83 & 13.84 & 14.04 & 12.22 & 2.9 & 17.4 & 16.9 & 5.4 & 5.4 \\
\hline$-0.07+0.05$ & 4.1 & 1.02 & 8.60 & 14.0 & 14.64 & 12.46 & 1.4 & 9.0 & 9.2 & 2.9 & 2.9 \\
\hline-0.05 & 3.6 & 1.42 & 6.81 & 15.0 & 15.63 & 13.33 & 1.7 & 6.4 & 8.6 & 2.8 & 2.7 \\
\hline Итого & 100.0 & 2.98 & 3.90 & 6.31 & 20.14 & 17.56 & 100 & 100 & 100 & 100 & 100 \\
\hline
\end{tabular}

Объектами исследования стали отходы обогащения апатит-нефелиновой руды, складированные в двух хвостохранилищах. Одно из них - законсервированное хвостохранилище, которое было сформировано во время работы АНОФ-1, когда в переработку вовлекались богатые руды с содержанием 19-22\% $\mathrm{P}_{2} \mathrm{O}_{5}$. Характеристика усредненной пробы отходов (ПХ-1), представлена в таблице 1. Второй объект - действующее хвостохранилище АНОФ-2, куда складируются отходы обогащения апатит-нефелиновых руд, начиная с 1970-х годов. Пробы были отобраны по периметру на пляжах 
дамбы с верхнего и нижнего горизонтов залегания: 150 м (ПХ-2-150) и 180 м (ПХ-2-180). По гранулометрическому составу пробы складированных отходов действующего хвостохранилища оказались более грубозернистыми по сравнению с пробой ПХ-1. Доля класса +0.315 в пробах ПХ-2 coставила 26.7-28.1 \%, что на порядок выше по сравнению с 2.5 \% для пробы ПХ-1 (табл. 1).

Анализ распределения основных компонентов по классам крупности показал, что для всех исследуемых проб в классах +0.16 мм характерно более высокое содержание $\mathrm{P}_{2} \mathrm{O}_{5}$. Приблизительно в этом же диапазоне крупности концентрируется и основная доля $\mathrm{Al}_{2} \mathrm{O}_{3}$, составляющая около 80 \%.

Минералогический анализ проб исследовали комбинированным способом с применением фазового, оптико-геометрического, иммерсионного и других методов исследования вещества. Проведенный минералогический анализ исследуемых проб показал (табл. 2), что пробы ПХ-2 более богаты апатитом по сравнению с пробой ПХ-1, причем большее количество апатита находится в нижних горизонтах действующего хвостохранилища.

Таблица 2. Минеральный состав проб ПХ-1, ПХ-2-150 и ПХ-2-180.

Table 2. Mineral composition of samples TS-1, TS -2-150 and TS -2-180.

\begin{tabular}{|c|c|c|c|}
\hline \multirow{2}{*}{ Минералы } & \multicolumn{3}{|c|}{ Содержание, \% } \\
\hline & ПХ-2-150 & ПХ-2-180 & ПХ-1 \\
\hline Апатит & 10.5 & 7.2 & 3.0 \\
\hline Нефелин ${ }^{*}$ & 48.5 & 54.2 & 56.5 \\
\hline Полевой шпат & 12.8 & 7.6 & 9.0 \\
\hline Гидрослюды & 1.5 & 1.3 & 0.5 \\
\hline Пироксенын* & 18.0 & 18.3 & 19.0 \\
\hline Титанит & 3.0 & 4.5 & 5.7 \\
\hline Титаномагнетит & 3.7 & 4.2 & 2.7 \\
\hline Прочие *** $^{* *}$ & 2.0 & 2.7 & 3.6 \\
\hline Итого: & 100.0 & 100.0 & 100.0 \\
\hline
\end{tabular}

Примечание: * - Совместно с нефелином учтена незначительная примесь фельдшпатоидных минералов содалита и канкринита; ** - цифра содержаний включает в себя небольшую примесь амфиболов; *** - в число «прочих» входит цеолиты, ильменит, лампрофиллит, лепидомелан, гидроксиды железа, перовскит; встречались эвдиалит, хлорит, сульфиды, циркон.

Общий вид проб ПХ-1 и ПХ-2 представлен на рисунке 1 (a, b, c).
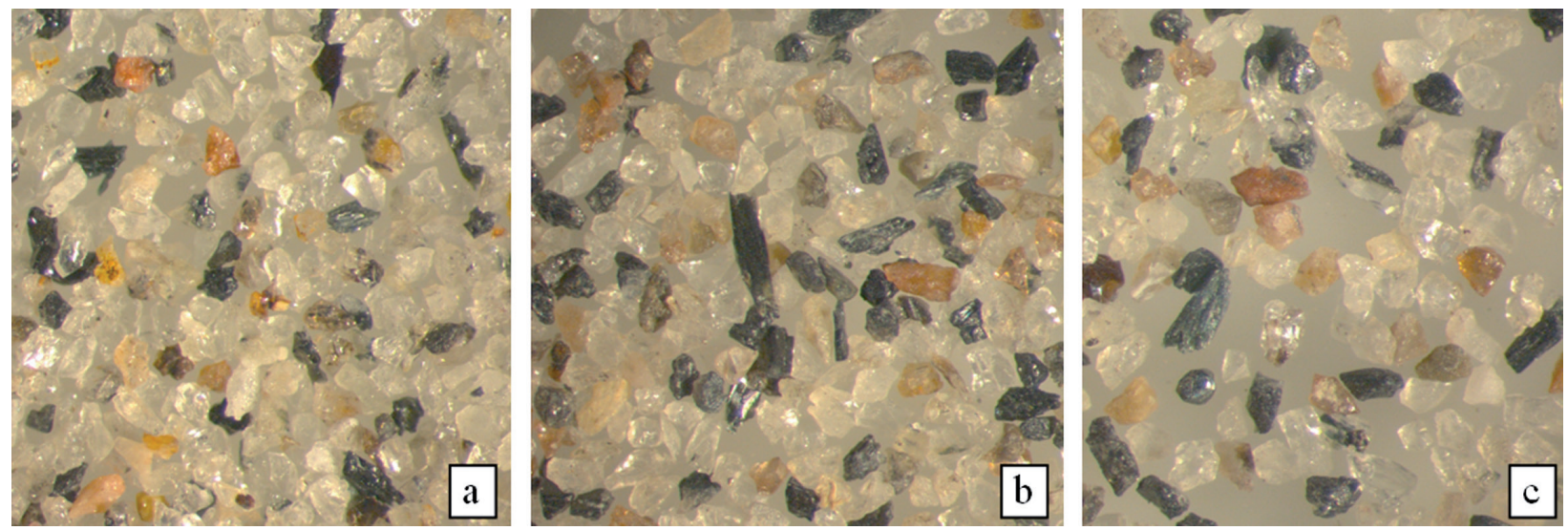

Рис. 1. Общий вид проб складированных отходов переработки апатит-нефелиновой руды класс $-0.2+0.16$ : а) ПХ-1; b) ПХ-2-150; с) ПХ-2-180.

Fig. 1. General view of samples of stockpiled apatite-nepheline processing waste, class $-0.2+0.16$ : a) TS-1; b) TS-2-150; c) TS-2-180. 

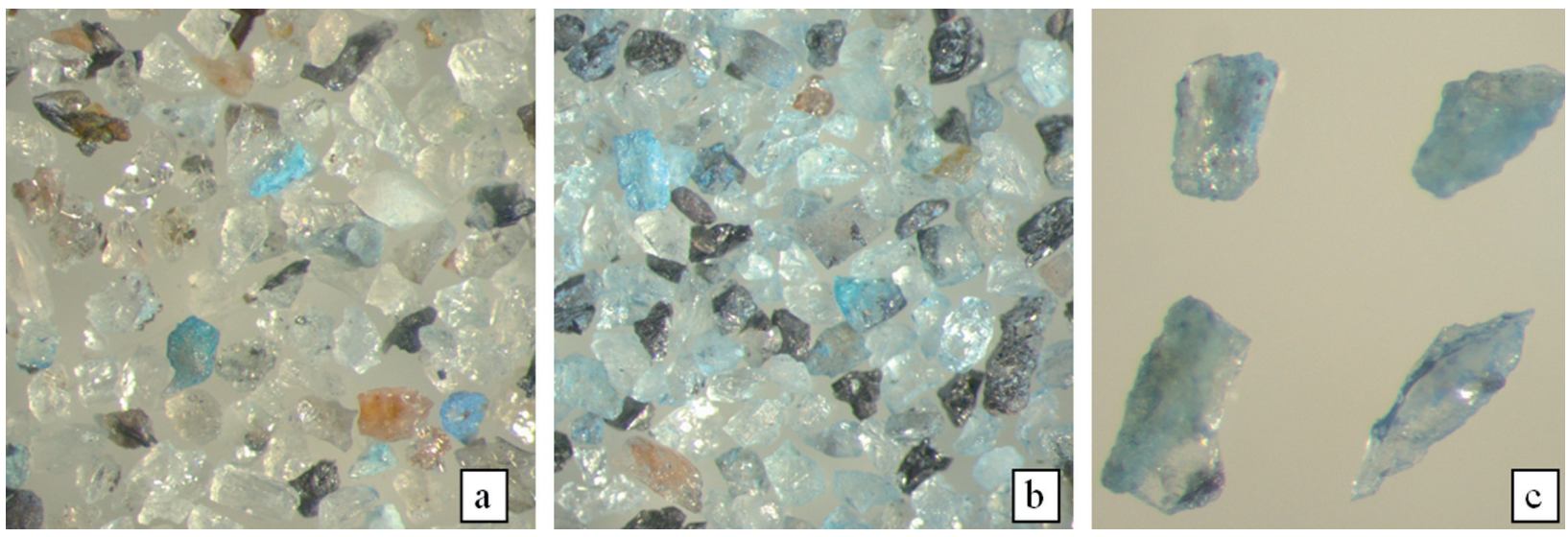

Рис. 2. Общий вид проб складированных отходов переработки апатит-нефелиновой руды после окрашивания метиленовым голубым, класс $-0.315+0.2$ : а) ПХ-1; b) ПХ-2-180; с) отдельные зерна нефелина из пробы ПХ-2-180.

Fig. 2. General view of samples of stockpiled apatite-nepheline ore processing waste after staining with methylene blue, class $-0.315+0.2$ : a) TS-1; b) TS-2-180; c) individual nepheline grains from TS-2-180 sample.

Оценка раскрытия сростков апатита показала, что апатит находится на 50 \% в свободном виде для проб ПХ-1 и ПХ-2-150 и на 60 \% для пробы ПХ-2-180. Сростки представлены разнообразными, часто полиминеральными срастаниями с эгирином, нефелином, гидрослюдой и титанитом. Свободный апатит в пробах ПХ-2 присутствует в виде типичных коротко- или длиннопризматических зерен с характерным сильным блеском и раковистым изломом. Встречаются единичные зерна апатита с примазками гидроксидов железа, которые обычно присутствуют и в исходной руде. В пробе ПХ-1 количество апатита значительно меньше, зерна оскольчатые, угловатые, их форма ближе к изометрической. Доля раскрытого нефелина и титанита в пробах ПХ-2 - 75-80 \%, в пробе ПХ-1 она увеличивается до 85-90 \%. Зерна нефелина в пробе ПХ-1 частично замещены гидрослюдами, 15-20 \% зерен имеют охристую и буроватую окраску (рис. 1 а). Для проб ПХ-2-150 и ПХ-2-180 характерно не только наличие зерен нефелина охристого цвета, но и примазки глинистых минералов (рис. 1 b, c).

Для оценки видоизменения нефелина и степени покрытия апатита высокодисперсными глинистыми минералами использовали способ сорбции красителя метиленового голубого. Окрашивание образцов проб по существующей методике (Ижак, 1967) показало, что основная масса апатита в пробе ПХ-1 не окрасилась, а, значит, имеет чистую поверхность без пленок, свободную от глинистых минералов. В пробах ПХ-2 зерна апатита приобрели голубой оттенок. Нефелин в пробе ПХ-1 в основном сохранил свой цвет, в том числе и зерна с частичным замещением нефелина гидрослюдами. Это говорит об отсутствии на них признаков более глубокого видоизменения в цеолиты и глинистые минералы. Имеющиеся в пробе зерна цеолитов и глинистых минералов окрасились в ярко синий цвет (рис. 2 а). Зерна эгирина и титанита в пробе ПХ-1 без видимых изменений, с чистой поверхностью. В пробах ПХ-2-150 и ПХ-2-180 значительная часть зерен нефелина, полевого шпата и темноцветных минералов оказались в большей или меньшей степени окрашенными в голубой цвет, что говорит о наличии на них примазок или пленок глинистых минералов (рис. 2 b, с).

Установленные минералогические особенности проб складированных отходов будут определять их технологические свойства. Невысокая степень раскрытия апатита в пробах определила необходимость предварительного доизмельчения проб. В измельченных пробах содержание класса + 0.16 мм составило $15-20 \%$, и 34-40 \% класса -0.071 мм. Измельчение руды до указанной крупности позволило очистить поверхность минералов от примазок глинистых минералов. В измельченных пробах ПХ- 2 после окрашивания зерна апатита не изменили свой цвет, зерна нефелина, эгирина и титанита также очистились от примазок глинистых минералов, за исключением единичных зерен (рис. 3 а). 

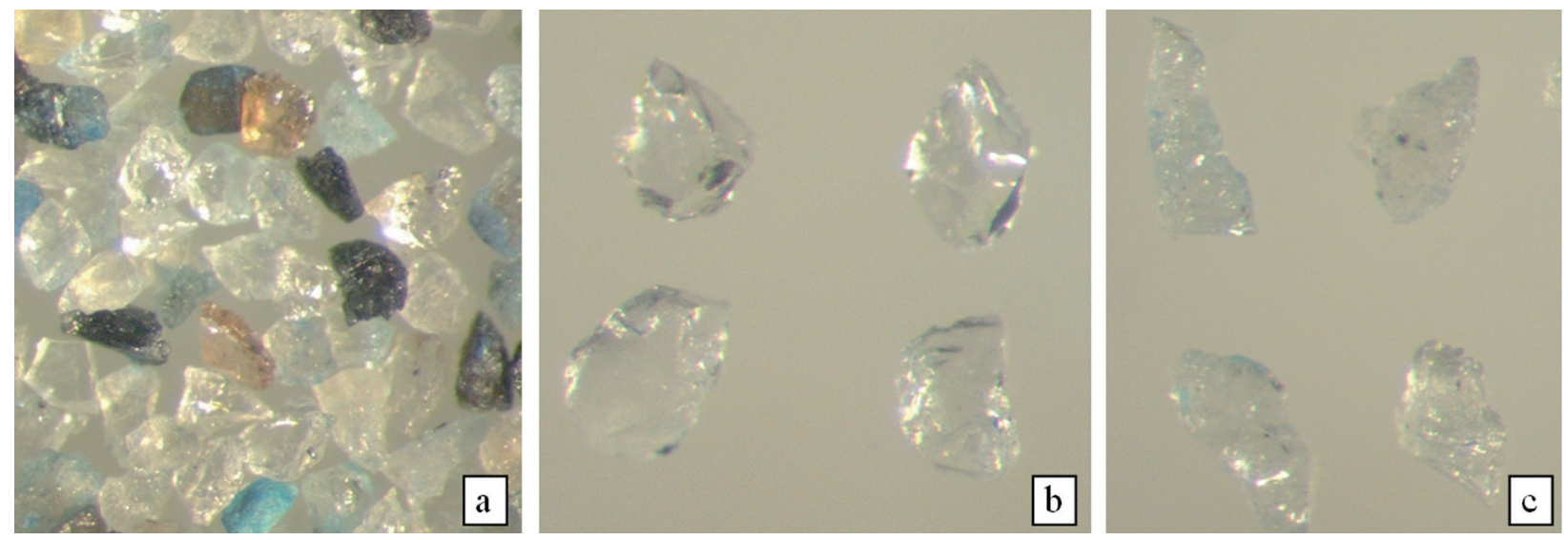

Рис. 3. Вид окрашенной измельченной пробы ПХ-2-180, класс -0,315+0,2 (a), зерен апатита (b) и нефелина (c), отобранных из окрашенной измельченной пробы ПХ-2-180.

Fig. 3. View of TS-2-180 stained grinded sample, class $-0.315+0.2$ (a); apatite grains (b) and nepheline grains (c) taken from TS-2-180 stained grinded sample.

Проведенные флотационные лабораторные исследования показали, что выделение апатита из проб ПХ-2-150 и ПХ-2-180 с применением традиционного реагентного режима не вызвало каких-либо трудностей. Удалось получить также, хоть и с применением более селективных реагентов, кондиционные нефелиновые и титанитовые концентраты, но только после доводки магнитной сепарацией.

\section{Выводы}

Изучены пробы отходов переработки апатит-нефелиновых руд, складированных в различные временные периоды. Методом сорбции красителя метиленового голубого показано наличие примазок или пленок тонкодисперсных глинистых частиц на поверхности зерен апатита одного из хвостохранилищ. Измельчение материала до флотационной крупности позволило очистить поверхность апатита, что определило возможность получения апатитового концентрата с содержанием 39 \% $\mathrm{P}_{2} \mathrm{O}_{5}$. Зерна нефелина в пробе ПХ-1 частично замещены гидрослюдами, в пробах ПХ-2 присутствуют признаки более глубокого видоизменения минералов, по поверхности нефелина, титанита, эгирина наблюдаются распространение цеолитов, глинистых минералов. При измельчении поверхность зерен минералов обновляется и в основном очищается от имеющихся примазок вторичных минералов. Присутствие минералов, вторично измененных по нефелину, в большей степени оказывает влияние на цикл нефелиновой флотации. Применение наиболее эффективных реагентных режимов в операции нефелиновой флотации и доводка черновых концентратов магнитной сепарацией позволяют получить из отходов переработки апатит-нефелиновых руд также и кондиционные нефелиновые и титанитовые концентраты.

Работа выполнена в рамках проекта КО1030 по Программе Kolarctic CВС «Исследование экологических, экономических и социальных воздействий на окружающую среду». «Эта публикация была подготовлена при содействии Европейского Союза. Исключительную ответственность за содержание этой публикации несут авторы: Г.В. Митрофанова, Е.В. Черноусенко, А.В. Артемьев, Е.Г Веселова. Публикация никоим образом не отражает взгляды Европейского Союза».

\section{Литература}

1. Аксенов Е.М., Садыков Р.К., Алискеров В.А., Киперман Ю.А., Комаров М.А. Техногенные месторождения - проблемы и перспективы вовлечения в хозяйственный оборот // Разведка и охрана недр. 2010. № 2. С. $17-20$.

2. Ижак Е.Я., Алейников Н.А. Минералогическая и химическая характеристики окисленных апатитонефелиновых руд // Обогащение апатитовых, вермикулитовых и перовскитовых руд. Л. Изд-во: Наука. 1967. С. 16-23.

3. Трубецкой К.Н. Основные направления и пути решения проблем ресурсосбережения при комплексном освоении недр // Маркшейдерия и недропользование. 2010. № 3. С. 22-29. 